\title{
EGFR NM_005228.3:c.2375T>A
}

National Cancer Institute

\section{Source}

National Cancer Institute. EGFR NM 005228.3:C.2375T>A. NCI Thesaurus. Code C147015.

A nucleotide substitution at position 2375 of the coding sequence of the EGFR gene where thymine has been mutated to adenine. 